\title{
The sound of potency: An observation study of nurses' approach to sound in a pediatric intensive care unit
}

\author{
Emma Mellgren ${ }^{1}$, Janet Mattsson*1,2,3 \\ ${ }^{1}$ Perioperative Medicine and Intensive Care, Karolinska University Hospital, Stockholm, Sweden \\ ${ }^{2}$ Karolinska Institutet, Department of Learning, Informatics, Management and Ethics, Sweden \\ ${ }^{3}$ Red Cross University, College Department of Health and Technology, Sweden
}

Received: March 1, 2017

DOI: $10.5430 /$ cns.v5n2p46
Accepted: April 23, 2017

URL: https://doi.org/10.5430/cns.v5n2p46

\begin{abstract}
Objective: The objective of this study was to investigate the nurses' approach to three sources of sound that contribute to high noise levels; alarms, doors that open and conversation.

Methods: Methods used derived from a theoretical perspective based on interpretive phenomenology and caring culture. In the pediatric intensive care, the caregivers of the children work in a high-tech environment as they are surrounded by sound from several sources. How caregivers understand and acknowledge how these sounds negatively affect a child's well-being depends on their individual knowledge and awareness of how children are affected by sound. In most cases, coming into an intensive care unit is a new experience for a child. This causes greater stress, both from the environment itself as well as from sound levels. The method was built on a phenomenological perspective and an interpretive non-participation, semi-structured observations were conducted in a pediatric intensive care unit (PICU) of one of Sweden's metropolitan regions in the winter of 2014-2015.

Results: The results show that noise is an overlooked phenomenon in the pediatric intensive care environment as it has given way to other priorities in the nurse's work. It is also apparent that this depends on the department's caring culture as it prioritizes other things, resulting in normalizing high levels of noise as a part of the pediatric intensive care environment.

Conclusions: Noise levels are not a priority in the department's caring culture. High noise levels are permitted unreflectedly and appears to be a token of potency and an accepted part of the health care environment.
\end{abstract}

Key Words: Pediatric intensive care, Sound levels, Caring culture, Rest

\section{INTRODUCTION}

Being a patient at a pediatric intensive care unit (PICU) implies a vulnerability, as the child is dependent on caregivers, often unable to express wishes or needs, and with limited opportunity to influence the environment. ${ }^{[1]}$

Previous research puts forward that noise levels in intensive care rooms often exceed internationally recommended levels, endangering patients' prospects for rest and recuper- ation. Recorded noise levels in a neonatal intensive care unit gives at hand that more assistive technology generates higher noise levels and increased frequency of alarms. This also results in staff having to talk louder. ${ }^{[2]}$ Research on nurses' understanding of and approaches towards the sound sources are, however, limited. Children admitted to a PICU is a small and vulnerable group that need sleep and rest to grow and develop. Since we know that nurses' priorities in their work has a direct effect on the child's well-being ${ }^{[1]}$ it

*Correspondence: Janet Mattsson; Email: Janet.mattsson@ @kh.se; Address: Red Cross University College Department of Health and Technology, Karolinska Institutet, Department of Learning, Informatics, Management and Ethics, Perioperative medicine and intensive care, Karolinska University Hospital, Murgrönsvägen 18, 12555 Älvsjö, Stockholm, Sweden. 
is of utmost importance to investigate this phenomenon in a highly technological environment as the pediatric intensive care ward.

\section{BACKGROUND}

Intensive care departments have in recent decades been given access to an increased amount of technical equipment and the ability to perform advanced nursing and medical interventions has increased. The high-tech health care implies a change in the health care environment and high levels of noise has become a significant everyday feature in this setting. This has been recognized as a global problem by the World Health Organization (WHO). WHO defines "noise" as "level of undesired sound" in its guidelines. ${ }^{[3]}$ Contrary, Konradsson, ${ }^{[4]}$ highlights the sound energy itself as the problem rather than the fact that sound can be undesired. In Sweden, the Public Health Agency's guidelines for acceptable noise levels in healthcare facilities and healthcare services follows the WHO recommendations. ${ }^{[5]}$ However, the joint message is that sound levels are too high in intensive care units in general. ${ }^{[6-8]}$

The main sources of noise are conversations in the patient rooms, alarms from medical equipment and doors closing or opening ${ }^{[7-9]}$ In a review article Konkani and Oakley ${ }^{[8]}$ compare several studies and conclude that the most frequent intervention to reduce high sound levels is education to change health care workers' attitudes and behavior. Hence, behaviors are closely linked to the caring culture in the department, which decides how children's caring needs are met and understood. ${ }^{[1]}$

\subsection{The sound effect on the pediatric intensive care pa- tient}

The perspective in this study rests on a theoretical standpoint in caring and refers to Patricia Benner's view that nursing is a caring relationship, p4: "an enabling condition of connection and concern."[10]

Children are described as a particularly vulnerable group regarding undesirably high sound levels. ${ }^{[3]}$ This needs to be considered, as caring means meeting children's needs, relieving their pain, avoiding suffering and promoting growth and health. ${ }^{[11]}$ High noise levels have been shown to increase stress in neonates ${ }^{[2]}$ that lead to frustration or anxiety. ${ }^{[7]}$ In fact, high sound levels can be the difference between life and death for a critically ill child due to the risk of high blood pressure, stimulated by stress deriving from high sound levels or other negative stimulation. ${ }^{[12]}$ When the child experiences stress and the blood pressure arises, fragile blood vessels are at risk to burst and hemorrhage into the brain. A risk significantly greater in young children than in adults. ${ }^{[12]}$

Published by Sciedu Press
Christensen ${ }^{[6]}$ points out sound level as an important part that supports recovery in the care environment. Unfortunately, sound is a low priority issue among staff, despite extensive research highlighting sound levels negative effect on children's rest and recovery. Pinheiro et al. ${ }^{[2]}$ argues that a reduction of noise levels probably would make staff more sensitive to sound and the negative impact on children could be reduced. Even though most audio sources in the PICU are difficult to eliminate, it is possible to influence how nurses choose to react to them. With the child's needs in the foreground it is possible to minimize excessive noise levels that generate stress in many patients.

\subsection{The importance of sleep}

Getting enough sleep at an early age is crucial for the child's neurocognitive development. ${ }^{[13]}$ Too little or poor sleep affects the child negatively and has an impact on an individual's future emotional and neurological characteristics. Nurses should promote children's health and recovery by attending to their daily need for sleep. Newborns need 16-19 hours/day while six year olds needs about 11 hours. ${ }^{[14]}$ However, an uninterrupted period of rest can be difficult to arrange during a stay in the PICU, since noise levels are high and often disturbing. Sleep is essential for the immune system, and most anabolic hormones has an increased secretion during sleep while the catabolic hormone decreases, which is important for the body's recovery. ${ }^{[14,15]}$ Also, the hemostatic regulation will be negatively affected the longer the patient is kept awake. ${ }^{[14]}$ Sleep deprivation increases the inflammatory response in the body and the risk of heart disease increases. ${ }^{[15,16]}$ Heart rate, urine output, and respiration rate decreases during sleep and one of the most important factors is the daily variation of light and darkness. A large part of the body's growth occurs during sleep, like the development of hearing. The baby needs to hear different tones and sounds that it recognizes from it's fetal stage to develop a hearing. Other types of sounds should be minimized to avoid overstimulation. ${ }^{[12]}$ Negative effects of high noise levels can be reduced if nurses become aware of how the work culture in the department contributes to the perception of the child and the care given. How the nurse cares for the children is influenced by the workplace caring culture. ${ }^{[1]}$

\subsection{Caring culture}

The caring culture encompasses the whole patient and all her needs; medical and nursing care, information, comfort, and the immediate environment around the patient. ${ }^{[17]}$ Bellot $^{[18]}$ uses almost the same words as he writes about organizational culture as something an organization owns, thus it is changeable, controllable and influenced by individuals included in the organization. Caring culture and organizational culture 
are occasionally used as synonyms; however, no consensus has yet emerged. ${ }^{[18-21]}$ It is however known that nurses in a high-tech environment such as the PICU, intensive care nurses experience difficulties in creating a calm environment in which to provide good care, as the need for medical care often collides with this caring intervention. ${ }^{[22]}$ This collision can be viewed as uncovering a conflict of what is accepted as most important to attend to in the caring culture surrounding the children. And as such influencing intensive care nurses' understanding of how important avoidance of undesired sounds is, to improve the children's possibility to sleep and enhance the quality of care. It is also evident that we need a change at the wards about the perception of the importance of caring interventions, compared to the necessity of medical and technological support. ${ }^{[1]}$ The challenge with high noise levels lies neither in a lack of research or lack of knowledge among staff about patients' need for sleep to recover. But high sound levels are overlooked or taken for granted in everyday work in the PICU. Benner et al. ${ }^{[10]}$ points out that how we experience a phenomenon such as high sound levels is dependent on the overall experience we have and how we perceive something here and now. As we are in a situation we direct our consciousness towards what in the situation that is meaningful to us. This is not interpreted in advance but decided there and then. ${ }^{[23]}$ By exploring how nurses approach sound in the PICU this study has the potential to contribute to increased knowledge of how to create a quieter care environment, with limited resources, that can lead to better care of and a faster recovery for critically ill children.

\subsection{Aim}

The aim of the present study is to explore how sound is approached in an everyday manner from the nurses' perspective in the PICU.

\section{METHOD}

\subsection{Design}

The choice to make a descriptive, observational study to answer the purpose of the study was adopted in accordance with Benner and Wrubel, ${ }^{[10]}$ and Benner's, ${ }^{[24]}$ descriptions of interpretive phenomenology, as we aim to explore how sound is approached in an everyday manner from the nurses' perspective in the PICU. Observing rather than interviewing was deemed most beneficial to uncover how individuals act generally and specifically in relation to how a phenomenon occurs in their everyday context. ${ }^{[10]}$ A non-participating semi-structured observation gives the observer the possibility to become a natural part of the study and to actively listen or observe the phenomena in its natural setting. ${ }^{\text {[25] }}$

\subsection{Setting}

The data was retrieved at a PICU in one of Sweden's metropolitan regions. The department cares for the most critically ill children in the country and carries 11-13 beds. Life-threatening conditions from infancy up to 15 years of age with surgical diagnoses are cared for and children with medical diagnosis are cared for between infancy up to 18 years of age. The patients' conditions often consist of failure of the vital organs, need for ventilator support, dialysis therapy, hypothermia therapy or circulatory support with inotropic drugs. All treatments require continuous monitoring and most patients are sedated.

\subsection{Participants}

A total of 11 specialist nurses were observed, 9 women and 2 men. At the ward, each nurse cared for two children at a time. The observations included children with various critical conditions aged from two days up to 16 years, 10 girls and 9 boys. The observations took place in different rooms to create a variation of data.

\subsection{Data}

All data collection was conducted by the first author (E.M.) and consists of 11 observations that were 60-120 minutes long each. The observer sat in a chair in the corner of the children's room to minimize any impact on the ongoing work. The observer was dressed in staff uniform to be accepted as a part of the working group of both children, their families and the staff. When spoken to the observer replied shortly and made clear that she would not be a part of any conversation during the time of observation, which was accepted by all. The observations took place during the day and evening shifts with the intention to cover variation over the day.

\subsection{The observation protocol}

To guide the observation and documentation process during the observations, an observation protocol was developed by the researchers and critically discussed with colleagues in the field. The protocol was based on previous research that highlighted the alarms from the equipment, doors that opens/closes and conversations among staff as the worst sources of stress in terms of sound. ${ }^{[7-9]}$ Number of alarms, from which monitor the alarm sounded and which patient alarm it concerned was registered in the observation protocol. The time span from when an alarm went off until the intervention took place, or the alarm was silenced, and which of the two that occurred first, was documented. If the nurse helper silenced the alarm it was documented if it was on the helper's own initiative or if the nurse requested it to be done. If the alarm went silent with intervention or if actively silenced by the caregiver was also documented. Silence in 
this observation protocol was defined as the absence of talk. In the observation protocol observations were divided into six 20-minute periods to identify longer quiet periods and short intensive periods.

To delineate the study only alarms originating from the monitor were documented. All children in the PICU are connected to this device that shows measures of oxygenation, heart rate, blood pressure, carbon dioxide and respiration rate. Conversations in the children's room were documented as they occurred. The observer noted what was said, whom the conversation concerned and how it was perceived - quiet, whispering or in a normal voice. Where conversations took place, in relation to the child, was also noted. Additionally, the number of openings and closings of the doors to the children's rooms were documented, as well as reasons for opening and closing. The observation protocol also documented background data of the nurse, like sex, age, years in the occupation, how the nurse perceived the severity of the child's condition and if she or he had set the sound level as well as the alarm limits after the work shift. The child's sex, age and condition was documented. In addition, the time of observation, duration of observation, number of observations, if the child was awake or asleep, sedated and body postures were also documented. The protocol also provided a space for the researcher's own reflections.

\subsection{Ethical considerations}

Before the observations started permission to execute the study was given by the head of the department and the ethical application No 2011/244/31-1, was approved by the Ethics Council, Karolinska Institute, Stockholm. The first author (E.M.) informed about the study and the aim of the study at the workplace on several occasions. Confidentiality procedures were followed and all informants that agreed to be observed was informed that they could stop observation at any time without questions being asked. In accordance with ethical principles the informants were asked again just before the observation took place if they allowed the observer to sit in the children's room and observe. They were also given the additional information that they should pay attention to the children in the room and their parents' reactions, and on their behalf, decide if the observations should be discontinued or not. This information was given due to the risk of observing the children and the parents even though they were not the focus of the observations. The children who were awake and the parents who were in the rooms were informed about the presence of the observer and asked for permission, in other cases, parents were informed about the observer's intentions and asked for permission. In all cases, approval was given.

Since no data was recorded at individual level; beyond age, gender and status; it is impossible to identify individuals in the data. Collected data is kept locked in and only the authors have access to it.

\subsection{Data analysis}

After the data was collected it was analyzed in accordance with Benner and Wrubel ${ }^{[10]}$ and Benner' ${ }^{[24]}$ description of interpretive phenomenology. The analysis moved back and forth between foreground and background, between situation and the practical worlds of the participants in three phases. Caring culture was used as raster in the analysis as it can be viewed as a common understanding of what is considered important and a priority of the individuals who work and operate within an enterprise.

The first step in the analysis begun in conjunction with the data collection and continued with reading and re-reading the observation documentation. The aim in the first phase was to familiarize with the data and to uncover patterns. Each observation was read several times to get an understanding of the parts and the whole. When the first author (E.M.) felt familiar with the data, an interpretive analysis begun where paradigm cases and exemplars were sought after, where nurses' interventions and the context were in focus. This phase was discussed with the second author (J.M.). In the third phase the authors (E.M., J.M.) again searched what was meaningful for the nurse in the situation. It meant to once again interpret the entire material, to find patterns and examples of data that clarified how an individual's behavior is a result of its environment and the current situation. ${ }^{[26]}$ As the paradigm cases were brought together the exemplars deepened or gave perspectives to the thematic analysis. Preliminary themes emerged of interpretations of how sound is approached in an everyday manner from nurses' perspective. The third phase also contained a triangulation of data and establishing descriptive names for aspects that the authors (E.M., J.M.) found prominent to the study aim. The purpose of naming was to capture examples of patterns of meaning in action, a meaning structure that includes a salient context and present the findings in a true way.

\section{Results}

Three qualitative variations of approaches to sound in closeness to the critically ill child were uncovered. They are presented as follows: The room as a situation, the room as a workplace and the room as a place to rest. A central phenomenon uncovered in the observations were how the caring culture normalized the sounds to the extent that they were neglected, unless called upon direct reaction in combination with other signs of critical incidents. Sound was accepted at high levels close to the child's ears. Noise levels increased 
when a new child arrived in the room or when the round came in. A fundamental difference was uncovered when the children's room was approached as a room for recovery. Then nurses actively kept a low sound level and arranged interventions accordingly. No connections between childrens' gender, age or medical status could be found.

\subsection{The room as a situation}

The analysis revealed how the sound gave a frame of severity and seriousness to the ongoing caring situation. By neglecting sounds and accepting them and their levels as something unavoidable, something that belonged there as a mark. A mark of that a severe and intensive situation is ongoing in this room. With the technical devices in the foreground, the technique is allowed to build a distance between the nurse and the child. As the child was connected to monitors, and controls were taken, the alarms sounded without visible action. The nurse glanced at the monitor, checking that it was ok, and continued with her work (obs. $3 \& 5$ ). Alarms could sound during nursing care interventions, as it was a normal feature and expected (obs. 2, $6 \& 11$ ). Or the sound could, in a more intense situation or when a new child arrived, sound for a long time or repeatedly until the alarms automatically turned themselves off (obs. $3 \& 7$ ). This approach to sound can be understood as legitimizing the high sound levels as a sign of importance, alarm sounds keep the situation and the technique in the foreground, signaling "something needs attention, or something might need attention very soon". Preparedness for any emergency was evident. However, the child's need for a calm environment was in the background, not attended to. The alarm limits and the sound of the alarm were not checked beforehand, or discussed as being a distress to the child. This was apparently visible when new children arrived, as an uncertainty developed about the role of the persons in the room, the medical condition of the child and the interventions that should follow. The sound framed the situation and gave a feeling of a highly technological and severe situation giving the nurse permission to focus on technology first and acting as the child was not the priority as the nurse strived to control the child's medical status and technical devices. In this situation, all information to team members, parents or staff that checks in to ask if they can be of help occurs in a loud voice over the child's bed (obs 1, $5 \& 9$ ). Doors open and close repeatedly without obvious purpose (obs. 1). No one seems aware of the child's need to feel safe or to shield the child from stressful sound.

\subsection{The room as a workplace}

One variation in the approach towards sound emerged in this theme, as nurses worked team based with other health care professionals. The conversations that take place concern the care of the child and how to get the work done. All conversations are work related and occurs over the head of the child or in closeness to the child. The sound in the room is approached in an office way of working and the room can be understood as a workplace where you get the job done and not a ward room where a child rests in sickness. Parallel conversations between staff occur (obs. 8), which results in raised sound levels. The round is held in the room bedside with as many as 11 physicians talking and arguing in loud voices about the child's condition and therapy as the child lays awake close by (obs. 1). When the alarm sounds the nurse silences it after checking on the child (obs. 10). Doors opens and closes with work related issues (obs. 1, 5, 6, 7, 8, $10,11)$. The work is in the foreground and sound seems to be taken for granted as a work-related phenomenon, something that just is.

\subsection{The room as a place to rest}

This theme uncovers a calmness and awareness of sound. The child is in the foreground, sheltered from stressful sounds in an aware and conscious way. The parents are attended to in a calm and clear way close by the child without high voices. The child's need for rest as well as a calm and secure environment is a priority, even in more critical situations (obs. 3). The nursing care interventions is done in silence, as the alarm is silenced before interventions starts (obs. 9). Communication with the parents is done in whispering voice (obs. 3). The environment appears calm and even when new children arrive sound levels and alarm limits are checked. Team members are encouraged, by the nurse, to speak in a low but distinct tone (obs. 9) and in the critical situation a calm and quiet approach can be maintained. The child is attended to during the more critical episodes and alarms are silenced (obs. 4, 9).

\section{DiscuSSION}

In our attempt to outline qualitatively different approaches to sound in the PICU and their impact on the child's need for rest, we uncovered three different approaches. The themes were as follows: The room as a situation, the room as a workplace and the room as a place to rest. The approaches shed light on the underlying caring culture in diverse ways and it became apparent that sound is viewed as a natural part of the PICU caring environment. However, it is approached in diverse ways. One reason for this might be that the caring culture allows the sound of technical devices to reflect positively on the nurses' status and competence to master a critical situation as shown in the theme: The room as a situation. Only in one theme, the room as a place to rest, was the child visible as a person with needs above strictly medical or technical needs. From a child's perspective, the high sounds 
from the alarms might be a source of stress. ${ }^{[7,8,12]}$ The child that arrives at a PICU most likely have no prior experience of what to expect or meet. When they arrive, people talk loudly, alarms sound, cords become attached to their body and the ward smell is different. When the child is dependent on the care in the PICU their bed becomes the nurse's workplace. But the bed is also the child's safe place. They might not have the possibility to express themselves or to communicate their feelings, experiences and desires. Additionally, staff are often unaware of how the patient perceives the environment. Mattsson et al. ${ }^{[1]}$ describe how nurses in emergency situations tend to be more medically oriented and focus less on the direct care of the child. This pattern is also found in the present study both in the acute phase and in stable situations where the underlying caring culture normalizes high sound levels, possibly exposing children to stress and other negative consequences. Rytterström, et al., ${ }^{[20]}$ describes that the individuals in the group shape its caring culture. Routines become meaningful only when nurses embrace and own them to give nursing care and when routines and procedures in the department's caring culture become joint endeavors. Routines that are ongoing and accepted as the caring culture are not reflected upon, like how sound is approached unreflectedly in this study. Conversations at bedside might be unavoidable, or calming to the child, giving them a sense of not being alone. ${ }^{[7]}$ And giving the child comfort and security is an essential part of the opportunity to rest and recovery. ${ }^{[12]}$ However, how we share information, what we talk about and how we talk can be arranged in a way that do not affect children negatively. Konkani \& Oakley ${ }^{[8]}$ points out that the most common and least costly way to reduce sounds are to educate staff about the negative impact it might have on the child's well-being. Pinheiro et al. ${ }^{[2]}$ argues that if the conversation volume and alarm volume is lowered, nurses would be more alert and respond more quickly to the alarm. A more aware approach to alarm and sound levels, as well as to the conversations and door openings daily at the round might create a new caring culture with the child's need for rest in the foreground. There are always limitations to research, also in this study. It is a small study and the data collected provides a snapshot of nurses' approach to sound levels in a PICU. It might not be transferable to all PICU environments. However, Mays and Pope ${ }^{[27]}$ argue that observations as data collection method is superior to other methods where the aim is to study the organizations and the individual's actions. Observations might also provide insight into phenomena the individual is unaware of. The authors would like to point out that transferability to other departments is not obvious, but not entirely impossible. The study highlights the complexity of the caring culture and the authors hope to bring light on an aspect that has been somewhat disregarded.

\section{Conclusions}

The present study aimed to investigate how the caring culture relates to sound levels at a PICU. The result shows that noise levels might not be a priority in a department's caring culture. High noise levels are often permitted unreflectedly and appears to be a token of potency, and an accepted part of the health care environment.

\section{Conflicts of InTERest Disclosure}

The authors declare they have no conflict of interest.

\section{REFERENCES}

[1] Mattsson J, Forsner M, Castrén M, et al. Caring for children in pediatric intensive care units: An observation study focusing on nurses' concerns. Journal of Nursing Ethics. 2013; 20(5): 528-38. PMid: 23329781. https://doi.org/10.1177/0969733012466000

[2] Pinheiro EM, Guinsburg R, Nabuco M, et al. Noise at the Neonatal Intensive Care Unit and inside the incubator. Revista Latino-Americana De Enfermagem (RLAE). 2011; 19(5): 1214-21.

[3] Guidelines for community noise. 1999.

[4] Konradsson K. Hearing. The first mind. In: Institutet K, editor. Mölnlycke: Karolinska Institutet University Press; 2011.

[5] The Public Health Agency's general advice on noise indoors. 2014; 13: 2001-7804.

[6] Christensen M. Noise levels in a general surgical ward: a descriptive study. J Clin Nurs. 2005; 14(2): 156-64. https : //doi .org/10.1 $111 / \mathrm{j} .1365-2702.2004 .01040 . \mathrm{x}$

[7] Johansson L, Bergbom I, Waye KP, et al. The sound environment in an ICU patient room-a content analysis of sound levels and pa- tient experiences. Intensive Crit Care Nurs. 2012; 28(5): 269-79. https://doi.org/10.1016/j.iccn.2012.03.004

[8] Konkani A, Oakley B. Noise in hospital intensive care units-a critical review of a critical topic. J Crit Care. 2012; 27(5): 522 e1-9. https://doi.org/10.1016/j.jcrc.2011.09.003

[9] Akansel N, Kaymakci S. Effects of intensive care unit noise on patients: a study on coronary artery bypass graft surgery patients. J Clin Nurs. 2008; 17(12): 1581-90. https://doi.org/10.1111/j.13 65-2702.2007.02144.x

[10] Benner PE, Wrubel J. The primacy of caring : stress and coping in health and illness. Menlo Park, Calif.: Addison-Wesley Pub. Co.; 1989. xxii, $425 \mathrm{p}$.

[11] Benner P. Reflecting on what we care about. American Association of Critical-Care Nurses. 2003; 12(2): 165-6.

[12] Ingman A, Åkerström S. NIDCAP: Newborn Individualized Developmental Care and assessment programs. In: Hospital KU, editor. Stockholm; 2011.

[13] Galland BC, Mitchell EA. Helping children sleep. Arch Dis Child 2010; 95(10): 850-3. https://doi.org/10.1136/adc.2009.1 
62974

[14] Ors M, Palm L. Sleep and wakefulness. In: Hanséus k, Lagercrantz H, Lindberg T, editors. Pediatrics. Lund: Studentlitteratur; 2012. 101-10 p.

[15] Åkerstedt T, Nilsson P. Sleep drawback as: an introduction. Journal of Internal Medicine. 2003; 254(1): 6-12. PMid: 12823638. https://doi.org/10.1046/j.1365-2796.2003.01195.x

[16] Kahn A, Van de Merckt C, Rebuffat E, et al. Sleep problems in healthy preadolescents. Pediatrics. 1989; 84(3): 542-6. PMid: 2788868.

[17] Watson JE. Caring science and human caring theory: Transforming personnel and professional practices of nursing and health care. Journal of Health \& Human Services Administration. 2009; 31(4): 446-82.

[18] Bellot J. Defining and assessing organizational culture. Nurs Forum. 2011; 46(1): 29-37. https ://doi.org/10.1111/j.1744-6198. $2010.00207 . \mathrm{x}$

[19] Hesselink G, Kuis E, Pijnenburg M, et al. Measuring a caring culture in hospitals: a systematic review of instruments. BMJ Open. 2013; 3(9): e003416. https://doi.org/10.1136/bmjopen-2 $013-003416$

[20] Rytterstrom P, Unosson M, Arman M. The significance of routines in nursing practice. J Clin Nurs. 2011; 20(23-24): 3513-22. https://doi.org/10.1111/j.1365-2702.2010.03522.x

[21] Scott-Findlay S, Estabrooks CA. Mapping the organizational culture research in nursing: a literature review. J Adv Nurs. 2006;
56(5): 498-513. https://doi.org/10.1111/j.1365-2648.20 $06.04044 . \mathrm{x}$

[22] Olausson S, Ekebergh M, Sterberg S. Nurses' lived experiences of intensive care unit bed spaces as a place of care: a phenomenological study. Nursing in Critical Care. 2014; 19(3): 126-34. PMid: 24646033. https://doi.org/10.1111/nicc. 12082

[23] Martinsson G, Wiklund-Gustin L, Lindholm C, et al. Being altruistically egoistic-Nursing aides' experiences of caring for older persons with mental disorders. Int J Qual Stud Health Well-being. 2011; 6(4): 1-12. https://doi .org/10.3402/qhw.v6i4.7530

[24] Benner P. The tradition and skill of interprative phenomenology in studying health, illness, and caring practices In: Benner P, editor Interprative Phenomenology: Embodyment, caring and ethics. Thousand Oaks, CA: Sage; 1994. https://doi.org/10.4135/9781 452204727.n6

[25] Polit D, Beck C. Nursing Research: Generating and Assessing Evidence for Nursing Practice. 9 ed. Philadelphia: Wolters Kluwer Health/Lippincott Williams \& Wilkins; 2012.

[26] Leonard V. A Heideggerian Phenomenological Perspective on the Concept of Person. In: Benner P, editor. Interpretive Phenomenology: Embodiment, Caring, and Ethics in Health and Illness. Thousand Oaks, CA: Sage; 1994. https://doi.org/10.4135/97814522 $04727 . n 3$

[27] Mays N, Pope C. Qualitative research: Observational methods in healthcare settings. British Medical Journal. 1995; 311(6998): 182-4. PMid: 7613435. https://doi.org/10.1136/bmj .311.6998.1 82 